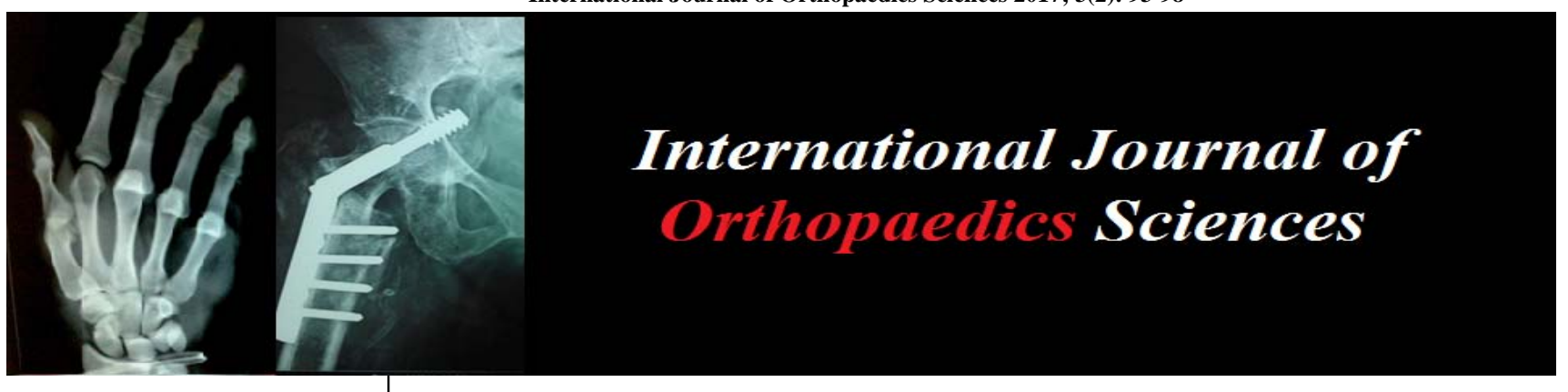

ISSN: $2395-1958$

IJOS 2017; 3(2): 93-98

(C) 2017 IJOS

www.orthopaper.com

Received: 18-02-2017

Accepted: 19-03-2017

Dr. Prashant Laxmichand Alwani Resident, Department of Orthopaedics, KIMS, Karad, Maharashtra, India

Dr. Pradeep Narhar Kulkarni Professor \& Head of Department, Department of Orthopaedics, KIMS, Karad, Maharashtra, India

Dr. Nishant Kiran Gaonkar Assistant Professor, Department of Orthopaedics, KIMS, Karad, Maharashtra, India

Dr. Gaurangkumar Chanchpara Resident, Department of Orthopaedics, KIMS, Karad, Maharashtra, India

Dr. Mihirkumar Solanki Resident, Department of Orthopaedics, KIMS, Karad, Maharashtra, India

Dr. Jayesh Balasaheb Pawar Resident, Department of Orthopaedics, KIMS, Karad, Maharashtra, India

Correspondence Dr. Prashant Laxmichand Alwani Resident, Department of Orthopaedics, KIMS, Karad, Maharashtra, India

\section{Displaced midshaft clavicle fractures: Conservative VS intramedullary nailing}

\author{
Dr. Prashant Laxmichand Alwani, Dr. Pradeep Narhar Kulkarni, Dr. Nishant \\ Kiran Gaonkar, Dr. Gaurangkumar Chanchpara, Dr. Mihirkumar Solanki and \\ Dr. Jayesh Balasaheb Pawar
}

DOI: http://dx.doi.org/10.22271/ortho.2017.v3.i2b.18

\section{Abstract}

Background: Clavicle fractures are most common and seen across all age groups. The traditional conservative treatment has shown higher incidences of fracture malunion, nonunion, and patient dissatisfaction. Aim is to analyze the outcome of clavicle fracture treated with Intramedullary nailing (IMN) with those treated conservatively in terms of rate of fracture union and functional outcome.

Materials \& Methods: In this prospective, randomized study of 40 cases with clavicle fracture 20 patients were treated conservatively and 20 with IMN and were followed up at 4th, 8th and 12th week and 6th and 12th month. Time for fracture union was measured radiographically and Functional Outcome was assessed using Constant Murley Shoulder score. Patients with pathological fractures, open fractures, comminuted fractures, segmental fractures and fractures associated with neurovascular injury were excluded.

Result: The mean time for fracture healing was significantly shorter in IMN group than conservative group with difference statistically highly significant $(p<0.005)$. There was statistically significant difference between two groups with respect to mean duration for radiological union for Naiking group $(p<0.0001)$ and also with respect to functional outcome at 6th $(p<0.0025)$, 9th $(p<0.003)$ and 12th $(p<0.002)$ month follow-up.

Conclusion: In this study Intramedullary Nailing of Midshaft Clavicle Fractures resulted in faster fracture union and Good Functional Outcome compared to those treated conservatively.

Keywords: Midshaft Clavicle fracture, operative versus conservative management, outcome, intramedullary nailing, Constant murley score

\section{Introduction}

Clavicle is the bony link from thorax to shoulder girdle and contributes to movements at shoulder girdle. Clavicle fracture is a common traumatic injury around shoulder girdle due to their subcutaneous position. Fracture of the clavicle accounts for approximately 5 to $10 \%$ of all fractures and upto $44 \%$ of injuries of the shoulder girdle. The majority of clavicle fractures $80-$ $85 \%$ occur in mid shaft of the bone where the typical compression forces applied to the shoulder and the narrow cross section of the bone combined and result in bony failure. Fractures of the clavicle have been traditionally treated non-operatively. In the past few years several publications have described about poor outcomes like malunion and nonunion (15\%) and poor functional outcome after conservative treatment of severely displaced midshaft clavicular fractures (MSCFs) ${ }^{[1,2]}$.

The proponents of early fixation of fresh clavicular fractures is to prevent complications like malunion and nonunion, emphasize the value of accurate reduction and fixation in affording quick pain relief and promoting early functional recovery ${ }^{[1,2]}$. In the publication ${ }^{[3]}$ author has described that clavicle can be treated with intramedullary methods like other long bones and thus it is a safe, quicker and minimal invasive procedure.

In this study we would like to analyze the outcomes of the operative management using intramedullary elastic nail and compare its results with older modality of conservative treatment considering it as standard treatment option. 


\section{Materials and Methods}

The present study was approved by local ethical committee which was carried out from May2014 to May2016 at Orthopaedics Department in Krishna Hospital and Medical Research Centre Karad. In a prospectively randomized study a total of 40 patients with displaced MSCFs were randomized into two equal groups, where one group was treated surgically with elastic intramedullary nailing and other group with figure of 8 Clavicle Brace(FCB). The cases were allotted to each group alternatively in an order to which they arrived to Krishna Hospital on OPD or IPD basis after signing Written Informed Consent. 20 participants were allotted to each group.

Inclusion criterias:1) All the displaced middle third clavicle fractures, 2) Compliant patients of 18-60 yr age who have active recreational lifestyle, 3) Comminuted fractures, 4)Mid shaft clavicular fracture associated with other injury, 5)Medically fit to undergo surgery (ASA grade 1-3).

Exclusion criterias: 1) Age $<16 y r s, 2$ ) Fractures older than 4 weeks, 3) Pathological fractures, 4)Open fractures, 5)Patient refusal, 6) Medically unfit (ASA Grade 4/5), 7)Previous fractures around the clavicle.

All the fractures were classified according to the Robinson's Classification [4] for Clavicle fractures. All patients in operative group were operated within 1 week from the date of admission.

\section{Conservative treatment technique (fig 1a, 1b)}

Patient was made to sit on stool with back facing surgeon, cotton was applied in axilla, and ready figure of 8 clavicle brace was applied after reducing the fracture by pushing proximal third of fracture. Figure of 8 clavicle brace was tightened to maintain position of clavicle and pulses on both sides were checked after applying brace. Patient was asked to report if he/she felt any tingling or burning sensation following application of brace. Patient's limb was immobilized in sling.

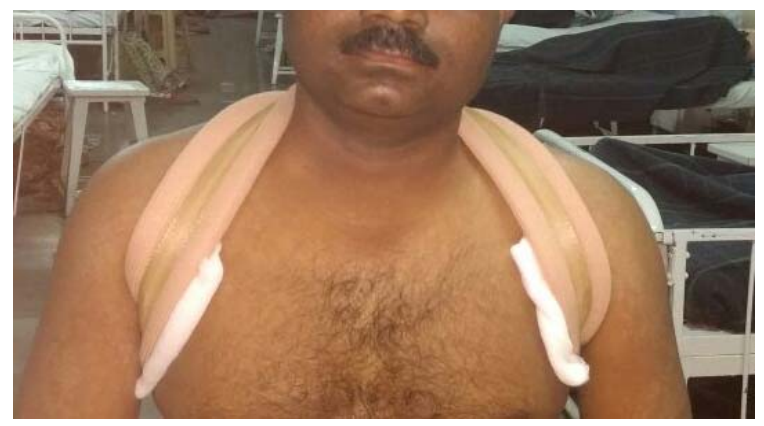

Fig 1: (a) - FCB (front)

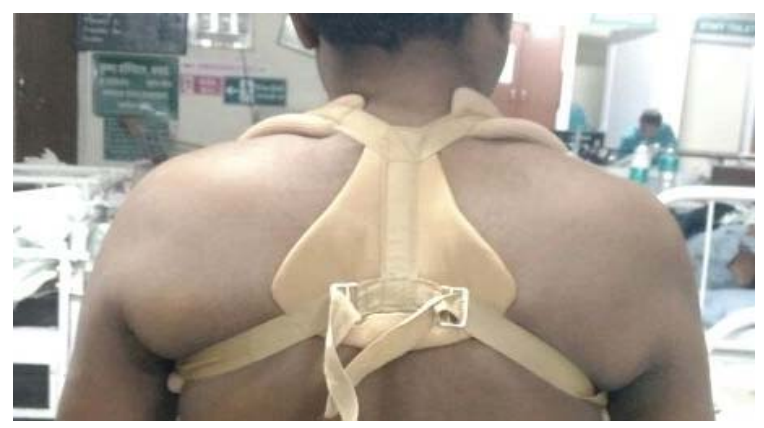

Fig 1: (b) - FCB (back)

\section{Surgical technique (fig2a-2e)}

After general anesthesia, the patients were positioned in the supine position with a rolled towel placed in interscapular region to provide extension of the shoulder girdle. The affected upper extremity was draped free to allow manipulation in a sterile manner. The image intensifier was placed in front of the surgeon on the opposite side of the operating table so that perpendicular shots and those with 20 $45^{\circ}$ of cephalic tilt and $45^{\circ}$ caudal tilt could be taken to view the I- and-S-shaped forms of the clavicle, respectively.

A small incision 1-2 cm long is made over the Medial end of clavicle $1 \mathrm{~cm}$ lateral to the sternoclavicular junction. Entry was made using a small curved or straight bone awl under the fluoroscopic control in AP and 45 degree Cephalic tilt and $45^{\circ}$ Caudal tilt view. Reaming of the medial fragment was done using manual reamers under fluoroscopic control. The nail, which is fixed to a universal chuck with a T-handle, is passed through entry point into the prereamed medullary canal under fluoroscopic control and allowed to exit from the medial fragment. Once the nail reached the fracture site, closed reduction by direct pressure on the fragments combined with manipulation of the arm was performed. The nail is next driven across the fracture site into the medullary canal of the lateral fragment until resistance is felt by the surgeon. To ensure the correct placement and depth of the nail into the lateral fragment, fluoroscopic control is used. The protruding end of the nail is cut off and bent as close to the bone as possible. Using the impact or, the bent end of the nail is impacted to prevent soft tissue irritation. The fascia and skin were closed in layers.

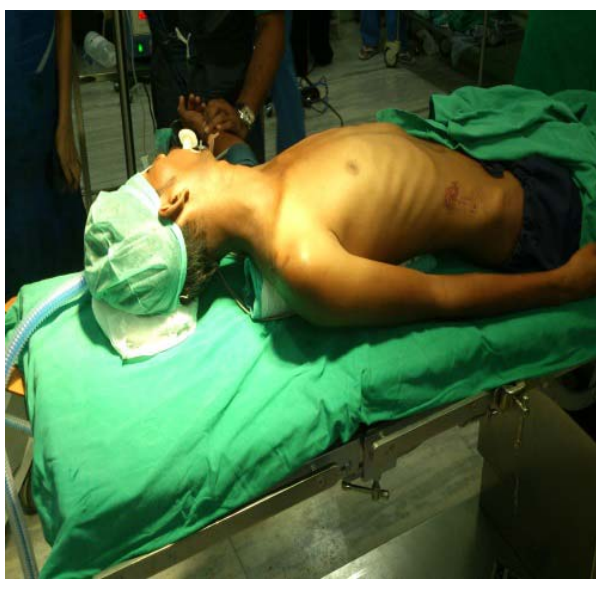

Fig 2: (a) - Patient's positioning

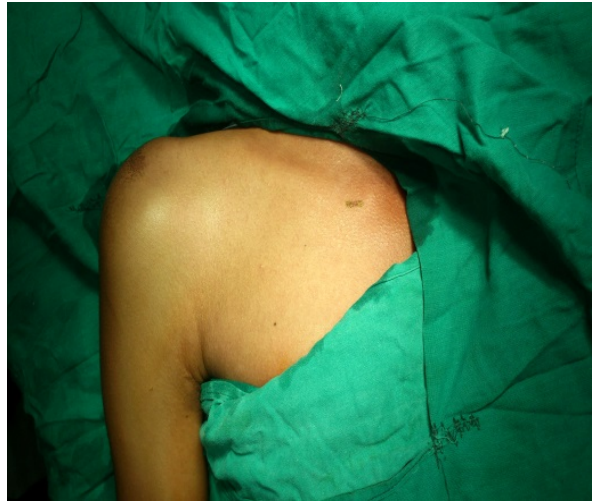

Fig 2: (b) Patient's draping with marked incision site and affected limb draped free for manipulation. 


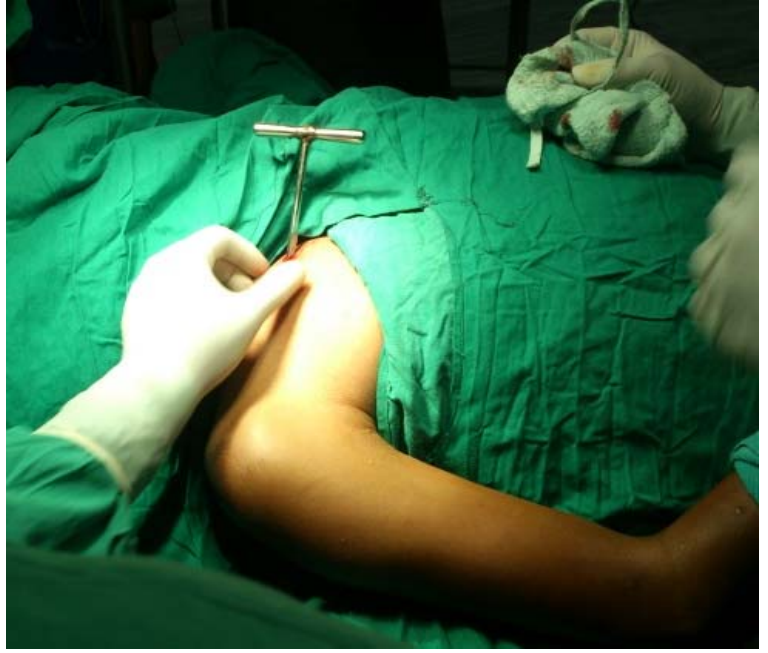

Fig 2: (c) Entry using bone awl

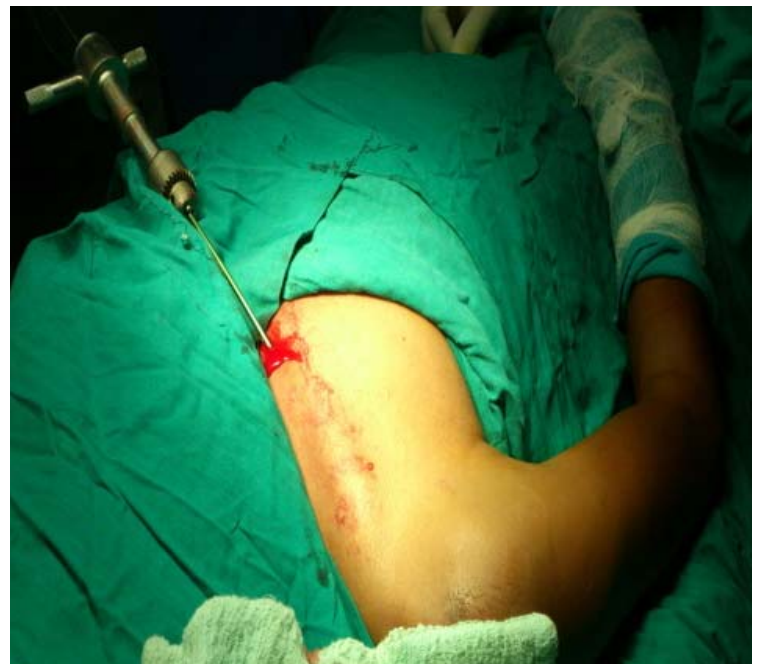

Fig 2: (d) - Nail insertion using t handle

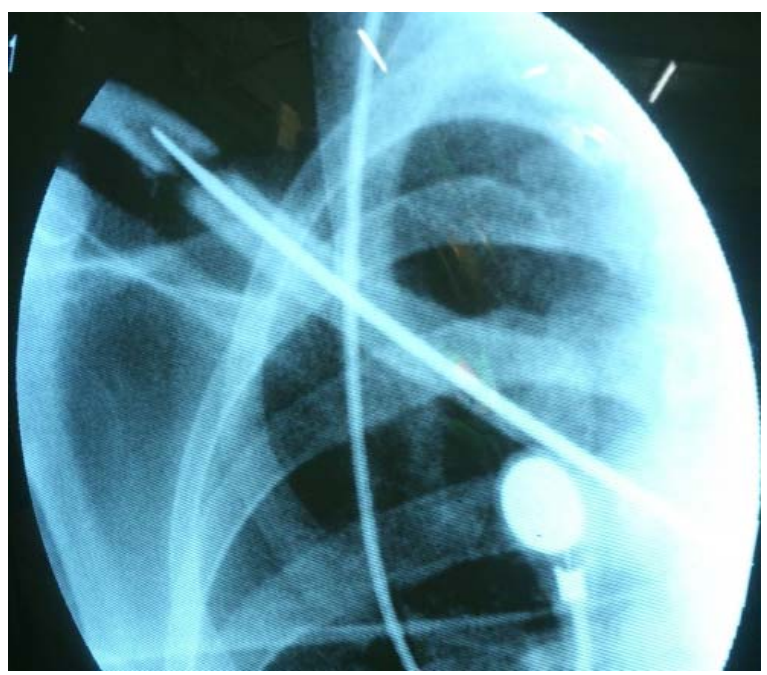

Fig 2: (e) Nail Position under C-ARM

\section{Assessment}

For both groups, patients received shoulder sling protection. In operative group it was continued for 2 weeks and in conservative group was for 6 weeks. Dressing was changed on post op day 2 and patient was discharged. Sutures were removed on post op day 10. Patient was then called for regular follow-up every week for 4 weeks and then at 8 weeks, 12 weeks, 6 months and 1 year.Local examination of the affected clavicle for tenderness, instability, deformity and shoulder movements was assessed. X-rays were taken at each follow up visit to assess the progress of fracture union and implant position.

The functional outcomes were assessed by Constant and Murley Score ${ }^{[5]}$ at 6 months, 9 months and 1 year. The patients were graded as Excellent if score ranges from 90-100, Good for 80-89, Fair for 70-79, and poor if score is less than 69. Radiographic healing was defined as obliteration of fracture line and bridging callus. Clinical union was defined as absence of tenderness at fracture site. Complications such as malunion, non-union, implant irritation, wound infection were recorded.

Statistical analysis was done by descriptive statistics as mean, $\mathrm{SD}$, proportions/percentages etc. Comparison of variables/ parameters in Operative and Conservative treatments groups was done by Student's Unpaired and Paired ' $t$ ' test at 5\% and $1 \%$ level of significance. $Z$ Test of proportion association was applied to test the difference between proportions of different variables in both the groups under the study. Statistical analysis software namely SYSTAT version 12 (made by Cranes software, Bangalore)

\section{Results}

Our study consists of 40 patients of fresh displaced mid shaft fracture of the clavicle who were treated surgically with titanium elastic nail and conservatively with figure of 8 clavicle brace between May 2014 to May 2016. All the patients were available for follow-up. Results were analyzed both clinically and radiologically.

In our study there were 30 males and 10 females with Right side of MSCFs seen in 28 patients. The mean average age in operative group was $31.80 \pm 11.23$ and in conservative group was $35.10 \pm 12.58$. Most of the MSCFs were due to RTA (road traffic accidents) which was seen in 33 pts, 2 were due to fall from height, 2 due to assault and 3 due to sport injuries. In our study MSCFs was associated with many other injuries such as Head injury in 5 pts, Mandible fractures in 2 pts, Chest trauma with rib fractures in 2 pts, Pelvic fractures in 3 pts and tibia fracture was seen in 2 pts. All the fractures were classified according to the Robinson's Classification. In our study we had 33 pts with type 2B1 fractures. (Table 1)

The union was assessed on the basis of radiographs, mean duration of union in operative group was $15.4 \pm 5.9$ weeks and in conservative group was $26.5 \pm 4.8$ weeks. Functional outcome was evaluated on the basis of Constant Murley Shoulder score at 6 months, 9 months and at 1 year which is described in Table 2.

Thus at final evaluation the overall grading of the results in operative group was 16 excellent and 4 good, while in conservative group there were 12 excellent, 5 good, 2 fair, and 1 poor results. Thus the values of Radiological Union and the Functional outcome in operative group are highly statistically significant as compared to the conservative group. Few complications (fig 5a to 5c) were also seen in our study in both the groups. There was 1 non union, 7 malunions and 1 delayed union in conservative group. Whereas in operative group there was 1 case of delayed union due to comminution at fracture site and 4 patients complained of medial cut end prominence with skin irritation, which ultimately went into implant removal after fracture union on opd basis under local anaesthesia. Thus the complication rate is minimal as compared to conservative group. 
Table 1: Characteristics of patients of both groups

\begin{tabular}{|c|c|c|c|c|}
\hline & \multicolumn{2}{|c|}{ Operative group } & \multicolumn{2}{c|}{ Conservative group } \\
\hline Male:female & 16 & 4 & 14 & 6 \\
\hline Right:Left & 12 & 8 & 16 & 4 \\
\hline Average Age (years) & $31.80 \pm 11.23$ & \multicolumn{2}{c|}{18} \\
\hline RTA & Cause of injury & \multicolumn{2}{c|}{1} \\
\hline Fall from height & \multicolumn{2}{|c|}{15} & 0 \\
\hline Sport Injuries & \multicolumn{2}{|c|}{1} & \multicolumn{2}{c|}{} \\
\hline Asssaut & 2 &
\end{tabular}

Table 2: Radiological and Functional Outcome

\begin{tabular}{|c|c|c|c|c|}
\hline & Operative Group (mean \pm SD) & Conservative Group (mean \pm SD) & 't' & P value* \\
\hline Radiological Union & $15.4 \pm 5.9$ & $26.5 \pm 4.8$ & 6.52 & $<0.0001$ \\
\hline \multicolumn{3}{|c|}{ Constant Murley score } \\
\hline 6 months & $84.2 \pm 9.1$ & $75.3 \pm 8.3$ & 3.23 & 0.0025 \\
\hline 9 months & $89.5 \pm 5.6$ & $82.1 \pm 6.2$ & 3.96 & 0.003 \\
\hline 1 year & $93.5 \pm 6.4$ & $87.6 \pm 4.7$ & 3.32 & 0.002 \\
\hline
\end{tabular}

$\mathrm{SD}=$ standard deviation, $\mathrm{t}=$ unpaired $\mathrm{t}$ test, ${ }^{*}=$ stat test

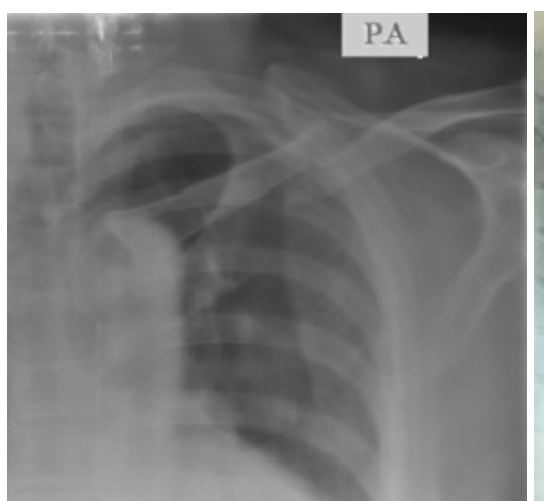

Fig 3a: Post Trauma

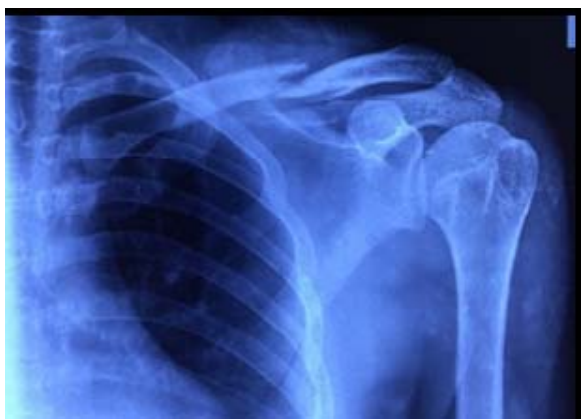

Fig 4a: Post Trauma

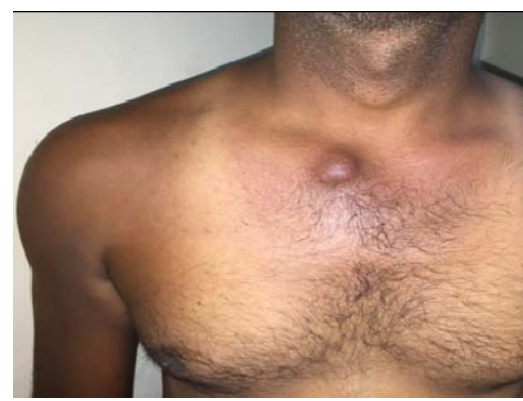

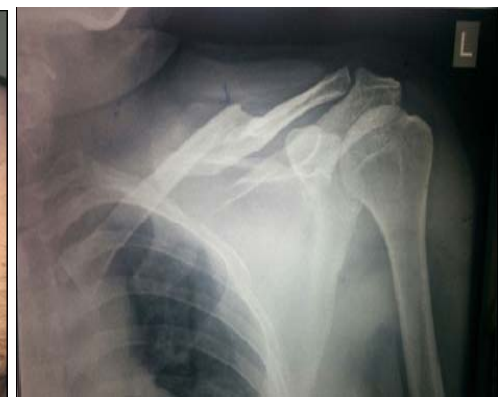

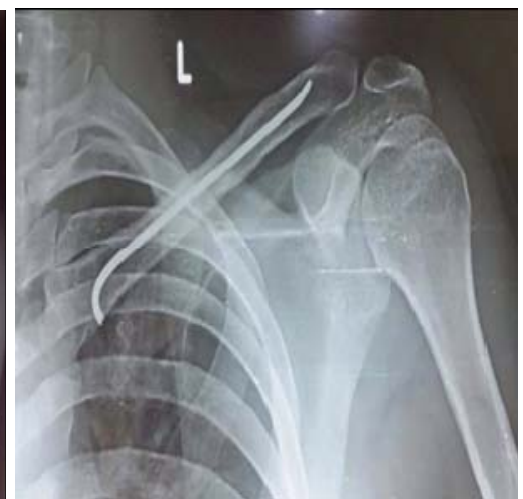

Fig 3b: Post-Op

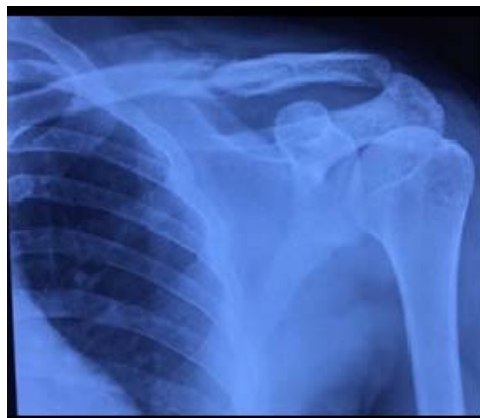

Fig 4b: 6 months Follow -up

Fig 3c: Follow-up radiograph with complete bone union at 6 months

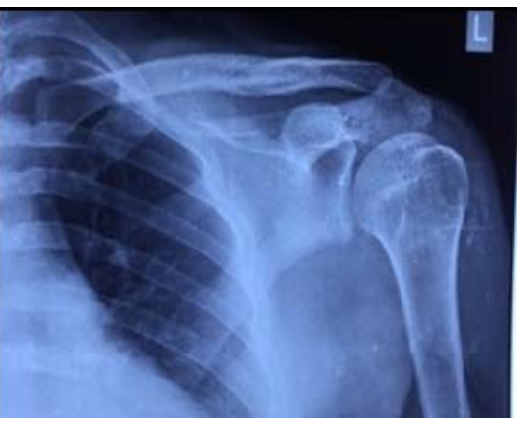

Fig 4c: Follow-up radiograph with complete bone union at 6 months.

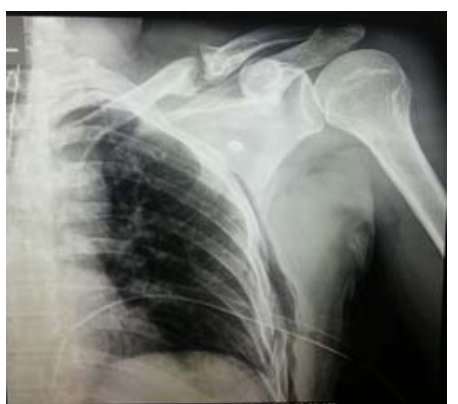

Fig 5a: Medial Cut End prominence in Nailing Group Fig 5b: Malunion in Conservative group Fig 5c: Nonunion in Conservative Group 


\section{Discussion}

Clavicle fractures for long have been treated with conservative means in form of sling, figure of 8 bandages, plaster etc in which there was union but with some deformity in displaced fractures. As the interest in operative treatment has increased it has progressed from open reduction and fixation to closed reduction and fixation. But still operative treatment has not replaced conservative treatment and most of clavicle fractures are usually treated conservatively.

In a study conducted to analyze the results of conservative treatment by Hill et al ${ }^{[6]}$ in 1997 , Nordqvist et al ${ }^{[7]}$ in 1998 and Robinson et al ${ }^{[4]}$ in 2004 found poor results following conservative treatment of displaced middle third clavicle fracture. In a meta-analysis of the literature from 1975 to 2005, Zlowodzki et al ${ }^{[10]}$ found that the non-union rate for non-operatively treated displaced midshaft clavicle fractures was $15.1 \%$, exponentially higher than previously described ${ }^{[1}$, ${ }^{8,9]}$. Good results with high union rates and low complication rates have been reported from a variety of techniques for primary fixation of displaced fractures of clavicle ${ }^{[1,11]}$. So there are specific indication like displacement, with or without comminution for middle third clavicle fracture (Robinson Type-2B1,2B2) for which operative treatment is needed.

Currently, plate fixation and intramedullary elastic nails are the available methods for severely displaced MSCFs. In this study, Intramedullary Nailing was compared with conservative management with Figure of Eight Clavicle Brace for displaced MSCFs in adults.

A total of 40 cases with MSCFs were selected for the study. Of these 20 patients were managed by nonoperative method with FCB and another 20 patients by Intramedullary Nailing. In this study, the average age of the patient was 31.80 years in operative group and 35.10 in conservative group, with the youngest patient being 20 years and the oldest being 55 years old, among them, male predominance was present $(75 \%)$ and female were $(25 \%)$. Pearson et al ${ }^{[12]}$ have reported the average age of patients sustaining a clavicular fracture is 33 years. Postacchini et al ${ }^{[22]}$ reported that most patients were men $(68 \%)$.

In this study, $80 \%$ developed clavicle fracture following RTA with direct impact on the shoulder girdle, followed by fall on out stretched hand in 5\%, physical assault in 5\% and due to sport injuries in $7.5 \%$. Zlowodzki et al ${ }^{[10]}$ and McKee et al

${ }^{[1]}$ described a fall or a blow to the shoulder, giving an axial compressive force on the clavicle, is the most common trauma mechanism of injury for any clavicular fracture.

Associated injuries commonly noted in this study were head injury in $12.5 \%$, Mandible fractures in $5 \%$, chest rauma in $5 \%$, pelvic fractures in $7.5 \%$ and tibia fracture in $5 \%$. Associated injuries have been reported in different studies ${ }^{[1}$, $10,12,13,14,15,16]$.

The mean time for fracture healing (radiological union) was shorter in the operative group (15.4 weeks) than nonoperative group (26.5 weeks). McKee et al ${ }^{[1]}$ described the mean time for fracture healing were 14-16 weeks for operated patients and 24-28 weeks for nonoperated patients.

The complications were more in the nonoperative group like symptomatic malunion 7 cases $(35 \%)$, non-union in 1 case $(5 \%)$ and Malunion in 1 case $(5 \%)$. The complications noted in the operative group were Medial cut end prominence in 4 cases $(20 \%)$ and delayed union in 1 case $(5 \%)$ due to comminution at fracture site. None of the operated patients had nonunion or malunion.

No infection was seen in the operative group. All surgical wounds healed between 8 and 12 postoperative days. Refracture and nonunion were seen in neither of the groups. McKee et al ${ }^{[1]}$ reported the rate of nonunion in the nonoperated patients $14-24 \%$, and $3.2 \%$ in the operated group.

Iatrogenic neurovascular vascular injury is an imminent complication if proper operative techniques are not followed. Because major neurovascular structures like subclavian vein, subclavian artery and brachial plexus are near to the surgical field $[17,18,19,20,21]$. However, in this study, none of our operated patients developed any neurovascular injury.

The Constant Murley Score at 6 month, 9 months and 1 year follow up was evaluated. Mean score for operative group was 93.5 and for conservative group was 87.6, which is statistically significant.

\section{Conclusion}

So elastic stable intra medullary nailing is recommended for all simple displaced midshaft clavicle fractures, for improved functional outcome, shorter time for union compared with nonoperative group at 1 year follow-up and minimal complications. Thus primary operative intervention in clavicle fracture in active adults may be of immense importance.

\section{References}

1. Michael D, Mckee. Clavicle fractures. In: Chapter 36, Robert W. Bucholz, James D. Heckman, Charles M. Court-Brown, and PaulTornetta (eds). Rockwood and Greens' fractures in adults, 7th edition, II, Philadelphia: Lippincott Williams and Wilkins. 2010; 1106-1141.

2. Edward A, Perez, Fractures of shoulder, arm, forearm. In Chapter 57, Campbell's operative orthopaedics, 12th edition, Philadelphia: Mosby Elsevier; 2013; 3:28362837.

3. Jamal EH, Assobhi. Reconstruction plate versus minimal invasive retrograde titanium elastic nail fixation for displaced midclavicular fractures. J Orthopaed Tramatol. 2011; 12:185-192.

4. Robinson CM, Court Brown CM, McQueen MM, Walkefield AE. Estimating the risk of nonunion following nonoperative treatment of a clavicular fracture. J Bone Joint Surgery (Am). 2004; 86:1359-1365.

5. Constant CR, Murley AHG. A clinical method of functional assessment of the shoulder. Clinical Orthopaedics and Related Research.1987; 214:160-164.

6. Hill JM, McGuire MH, Crosby LA. Closed treatment of displaced middle third fractures of the clavicle gives poor results. J Bone Joint Surgery (Br), 1997; 79:537-540.

7. Nordgvist A, Petersson CJ, Redlund-Johnell I. Mid clavicular fractures in adults: end result study after conservative treatment. J OrthopTrauma. 1998; 12:572576.

8. Mark Kettler, Matthias Schieker, VokerBraunstein, Matthias Konig and Wolf Mutschler. Flexible intramedullary nailing for stabilization of displaced midshaft clavicle fractures. ActaOrthopaedica, 2007; 78(3):424-429.

9. VinzenzSmekal, Alexander Irenberger, Rene El Attal, Juergen Oberladstaetter, DietmarKrappinger, Franz Kralinger. Elastic stable intramedullary nailing is best for mid-shaft clavicle fractures without comminution. Injury 2011; 42(4):324-329.

10. Zlowodzki M, Zelle BA, Cole PA, Jeray K, McKee MD. Treatment of acute midshaft clavicle fractures: Systematic review of 2144 fractures. J Orthop Trauma. 
2005; 19:504-7.

11. Ruedi T, Duwelins PJ. Fractures and dislocations of the shouldergirdle and humerus. Chapter-15, In: Chapman MW, editor, Chapaman'sorthopaedic Surgery, Philadelphia, Lippincott Williams and Wilkins, $3^{\text {rd }}$ edition 2001; 444-450.

12. Pearson AM, Tosteson AN, Koval KJ, McKee MD, Cantu RV, Bell JE, et al. Is surgery for displaced, midshaft clavicle fractures in adults cost-effective? Results based on a multicenter randomized, controlled trial. J Orthop Trauma. 2010; 24:426-33.

13. Gille J, Schulz A, Wallstabe S, Unger A, Voigt C, Faschingbauer M. et al. Hook plate for medial clavicle fracture. Indian J Orthop. 2010; 44:221-3.

14. Thyagarajan DS, Day M, Dent C, Williams R, Evans R. Treatment of mid-shaft clavicle fractures: A comparative study. Int J Shoulder Surg. 2009; 3:23-7.

15. Canadian Orthopaedic Trauma Society. Nonoperative treatment compared with plate fixation of displaced midshaft clavicular fractures. A multicenter, randomized clinical trial. J Bone Joint Surg Am. 2007; 89:1-10.

16. Garg AK, Mukhopadhyay KK, Shaw R, Roy SK, Banerjee K, Mukhopadhyay K. Displaced middle-third fractures of the clavicle-operative management. J Indian Med Assoc. 2011; 109:409-10.

17. Khan MA, Vakati SR. Management of clavicular nonunion with plate fixation and bone grafting. Arch Int Surg 2013; 3:49-51.

18. Böhme J, Bonk A, Bacher GO, Wilharm A, Hoffmann R, Josten C. et al. Current treatment concepts for mid-shaft fractures of the clavicle-results of a prospective multicentre study. Z Orthop Unfall 2011; 149:68-76.

19. Stegeman SA, de Jong M, Sier CF, Krijnen P, Duijff JW, van Thiel TP, et al. Displaced midshaft fractures of the clavicle: Non-operative treatment versus plate fixation (Sleutel-TRIAL). A multicentre randomised controlled trial. BMC Musculoskelet Disord 2011; 12:196.

20. Giorgi SD, Notarnicola A, Tafuri S, Solarino G, Moretti L, Moretti B. et al. Conservative treatment of fractures of the clavicle. BMC Res Notes 2011; 4:333.

21. Van der Meijden OA, Gaskill TR, Millett PJ. Treatment of clavicle fractures: Current concepts review. J Shoulder Elbow Surg 2012; 21:423-9.

22. Postacchini F, Gumina S, De Santis $P$, Albo F. Epidemiology of clavicle fractures. J Shoulder Elbow Surg 2002; 11:452-6. 